\section{Esmolol for the treatment of recurrent ventricular tachycardia}

\author{
Simone Savastano, Alessandra Greco, \\ Benedetta Matrone \\ Cardiology Department, San Matteo \\ Hospital, Pavia, Italy
}

\begin{abstract}
Cardiac arrest and electrical storm are two major emergencies. The use of beta blockers in these clinical conditions has been proposed; however, definite data about the emergency use of beta blockers in recurrent ventricular tachycardia with pulse have never been published. We report two cases of recurrent ventricular tachycardia, which were unresponsive to the standard pharmacological treatment but successfully responsive to esmolol infusion. Both cases showed a reduced left ventricle ejection fraction due to an acute myocardial infarction and to an idiopathic dilated cardiomyopathy respectively. Nevertheless, the use of esmolol was shown to be both safe and effective without inducing low output syndrome.
\end{abstract}

\section{Introduction}

The protective role against ventricular arrhythmias of oral administration of beta blockers in patients with catecholaminergic polymorphic ventricular tachycardia ${ }^{1}$ or with ST-segment elevation myocardial infarction (STEMI) $^{2}$ has been shown, however there is very little evidence about the use of intravenous beta blockers for the treatment of recurrent ventricular tachycardias. In this regard we report two cases of recurrent ventricular tachycardia effectively solved by intravenous administration of esmolol.

\section{Pharmacology of esmolol}

Esmolol is an ultra-short-acting b1-selective adrenergic blocker (mean elimination half-life $\left[\mathrm{t}^{1} 12\right]=9$ minutes) with rapid onset and offset of effects that provided an element of safety. When esmolol is administered as a bolus followed by continuous infusion, onset of activity occurs within 2 minutes, with $90 \%$ of b-blockade at 5 minutes. Full recovery from its effect takes 18-30 minutes after stopping the infusion. Generally, a loading dose of $500 \mathrm{mcg} / \mathrm{kg}$ over one minute is administered prior to a maintenance infusion dose of $50-300$ $\mathrm{mg} / \mathrm{kg} / \mathrm{min}$. Esmolol is metabolized by red blood cells' esterases to an acid metabolite (ASL-8123) and methanol. It makes esmolol safe even for those patients with renal or hepatic dysfunction. Pharmacokinetic interactions of esmolol with other cardiovascular drugs have been studied without finding any of clinical interest. The most common adverse effect with esmolol is hypotension. The incidence of hypotension (0-50\%) increases with bolus doses of $100 \mathrm{mg}(25 \%)$ to $200 \mathrm{mg}(33 \%)$ or continuous infusions exceeding 150 $\mathrm{mg} / \mathrm{kg} / \mathrm{min}$. Hypotension can be easily managed by decreasing the dose or stopping the infusion. Due to its characteristics esmolol is suitable for emergency rooms, critical care units and surgical settings where rapid control of heart rate or blood pressure is often needed.

\section{Case Report}

The first case is about a 47-year-old woman, who came to our attention for anterior myocardial infarction (STEMI). A primary percutaneous coronary intervention on the left anterior descendant artery was performed in a single vassel disease. Circulation was supported by an intra-aortic balloon pump (IABP) and epinephrine infusion. The left ventricular function was depressed (LVEF 30\% at echo). The patient was then stabilized; IABP was removed and epinephrine infusion was stopped. Eight days later, she suffered an episode of sustained monomorphic VT at $220 /$ min perceived as simple palpitations; blood pressure was $73 / 49 \mathrm{mmHg}(85 / 50 \mathrm{mmHg}$ during sinus rhythm). Lidocaine $100 \mathrm{mg}$ was administered unsuccessfully, so she was sedated and converted to sinus rhythm with $200 \mathrm{~J}$ synchronized DC shock. From that moment on six other arrhythmic relapses occurred, for a total of seven DC shocks, despite the infusion of amiodaron $(20 \mathrm{mcg} / \mathrm{kg} / \mathrm{min})$ and lidocaine (20 $\mathrm{mcg} / \mathrm{kg} / \mathrm{min}$ ). After the last cardioversion an infusion of esmolol $50 \mathrm{mcg} / \mathrm{kg} / \mathrm{min}$ was started and the patient stabilized, without any other relapse. There was no mechanical cause for the arrhythmia (Figure 1A)

The second case is about a 71-year-old man with an idiopathic dilated cardiomyopathy (LVEF $28 \%$ at echo) and normal coronary arteries. He was admitted because of an appropriate ICD intervention. During the hospitalization he suffered another episode of VT refractory to antitachycardia pacing (ATP) and evolving into ventricular flutter treated with DC shock. In the following hours he had incessant episodes of haemodynamically well-tolerated VT, not responding to medical treatment with intravenous lidocaine (100 $\mathrm{mg}$ bolus and then infusion $20 \mathrm{mcg} / \mathrm{kg} / \mathrm{min}$ ), intravenous flecainide $(1 \mathrm{mg} / \mathrm{kg})$, amiodarone (150 mg plus $300 \mathrm{mg}$ bolus), and several attempts of ATP.
Correspondence: Simone Savastano, Cardiology Department, San Matteo Hospital, piazzale Golgi, 27100 Pavia, Italy.

Tel: +39.0382.501590 - Fax: +39.0382.501279.

E-mail: s.savastano@smatteo.pv.it

Key words: Esmolol; Ventricular tachycardia; Electric storm.

Contributions: the authors contributed equally.

Received for publication: 17 June 2016.

Revision received: 4 September 2016.

Accepted for publication: 6 September 2016.

This work is licensed under a Creative Commons Attribution 4.0 License (by-nc 4.0).

(C) Copyright S. Savastano et al., 2016

Licensee PAGEPress, Italy

Emergency Care Journal 2016; 12:6097

doi:10.4081/ecj.2016.6097

The patient was cardioverted eight times with external and internal DC shock. The arrhythmias stopped when esmolol therapy was instituted, with an initial bolus of $40 \mathrm{mg}$ followed by an infusion of $50 \mathrm{mcg} / \mathrm{kg} / \mathrm{min}$ for two hours. No relapse of ventricular arrhythmia was observed and in the following days (Figure 1B).

\section{Discussion}

Cardiac arrest (CA) and electrical storm (ES) are two major and often fatal emergencies. During ventricular tachycardia (VT) or ventricular fibrillation (VF) a marked increase of plasma concentration of epinephrine has been demonstrated ${ }^{3,4}$ and this may play an important role in sustaining arrhythmias. Moreover a denervation supersensitivity to catecholamine has been described after myocardial infarction ${ }^{5}$ and this may have been one of the mechanisms involved in the first case presented. From here the hypothesis of using beta blockers on top of antiarrhythmic therapies was formulated. Esmolol is a cardio-selective betal-receptor blocking agent with a rapid onset and a short duration of action ( $\mathrm{t} 1 / 2=9$ minutes) ${ }^{6}$ The efficacy of esmolol has been successfully tested both during $\mathrm{CA}$ due to refractory $\mathrm{VF}^{7-11}$ increasing ROSC and survival and during pulseless ES ${ }^{12}$ overcoming ACLS drugs. However the efficacy of esmolol in treating hemodynamically tolerated ventricular arrhythmias has never been described and so we reported these two cases. Notably we used esmolol in two patients with a significantly reduced left ventricle ejection fraction without inducing a low output syndrome 

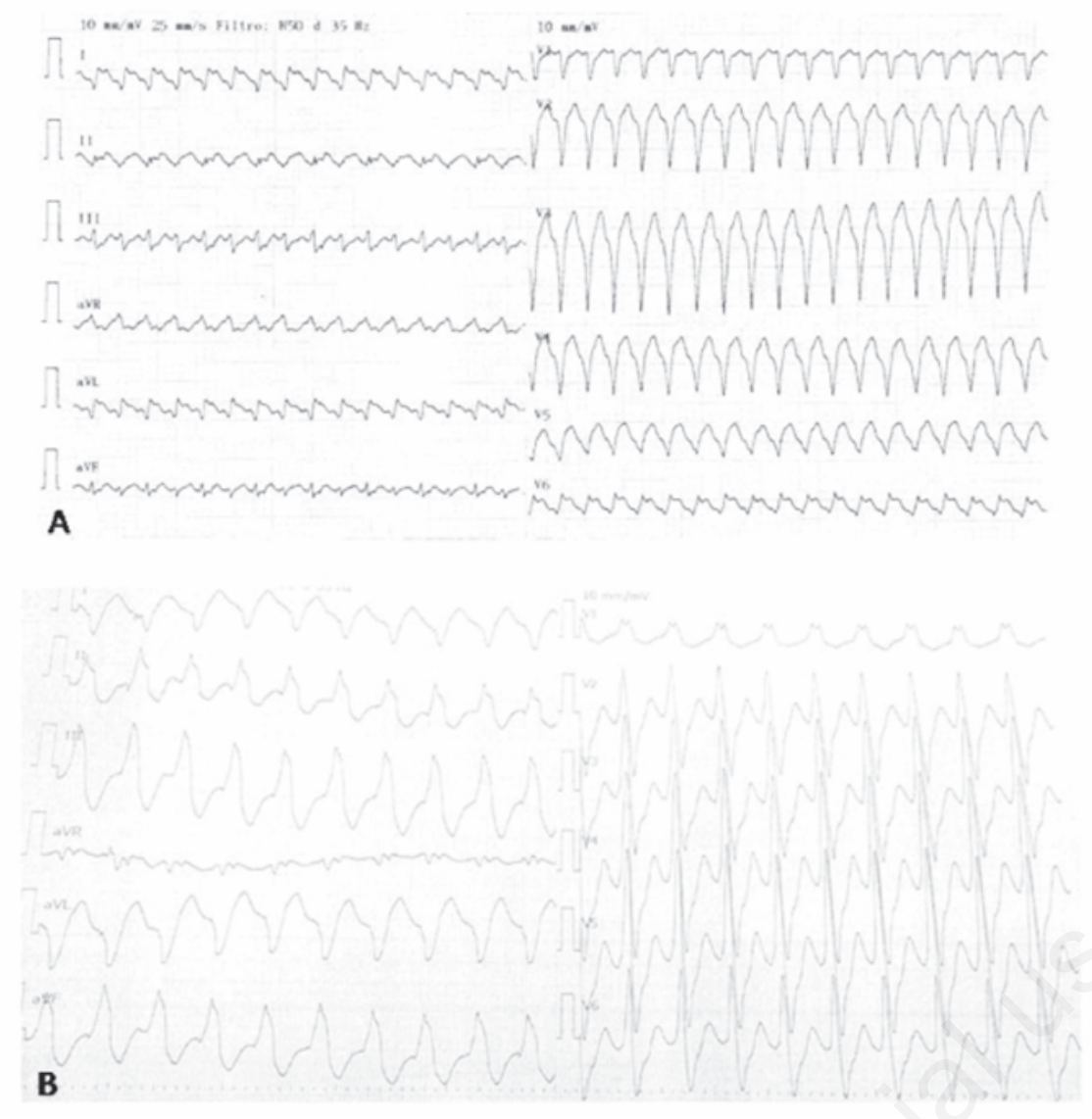

Figure 1. Ventricular tachycardia of the two patients (A the first case and $B$ the second).

\section{Conclusions}

Esmolol can be safely and effectively used for the treatment of arrhythmic storm and it may represent an additional weapon for patients with hypotension and reduced ejection fraction.

\section{References}

1. Van der Werf C, Lieve KV. Beta-blockers in the treatment of catecholaminergic polymorphic ventricular tachycardia. Heart Rhythm 2016;13:441-2.

2. Park KL, Goldberg RJ, Anderson FA, et al. Global registry of acute coronary events investigators. Beta-blocker use in ST-segment elevation myocardial infarction in the reperfusion era (GRACE). Am J Med 2014;127:503-11.

3. Kern KB, Elchisak MA, Sanders AB, et al. Plasma catecholamine and resuscitation from prolonged cardiac arrest, Crit Care Med 1989;17:786-91.

4. Lindner KH, Haak T, Keller A, et al. Release of endogenous vasopressors during and after cardiopulmonary resuscitation. Heart 1996;75:145-50.

5. Zipes DP. Influence of myocardial ischemia and infarction on autonomic innervation of heart. Circulation 1990;82:1095-105.

6. Wiest DB, Haney JS. Clinical pharmacokinetics and therapeutic efficacy of esmolol. Clin Pharmacokinet 2012;51:347-56

7. Killingsworth CR, Wei CC, Dell'Italia LJ, et al. Short acting b-adrenergic antagonist esmolol given at reperfusion improves survival following prolonged FV. Circulation 2004;109:2469-74.

8. Cammarata G, Weil MH, Sun S, et al. Beta 1 adrenergig blockade during cardiopulmonary resuscitation improves survival. Crit Care Med 2004;32:440-3.

9. Driver BE, Debaty G, Plummer DW, Smith SW. Use of esmolol after failure of standard cardiopulmonary resuscitation to treat pa4-tients with refractory ventricular fibrillation. Resuscitation 2014;85:133741.

10. Jingjun L, Yan Z, Weijie Dongdong Z, et al. Effect and mechanism of esmolol given during cardiopulmonary resuscitation in a porcine ventricular fibrillation model. Resuscitation 2009;80:1052-9.

11. de Oliveira FC, Feitosa-Filho GS, Ritt LE. Use of beta-blockers for the treatment of cardiac arrest due to ventricular fibrillation/pulseless ventricular tachycardia: a systematic review. Resuscitation 2012;83:674-83.

12. Nademanee K, Taylor R, Bailey WE, et al. Treating electrical storm: sympathetic blockade versus advanced cardiac life support-guided therapy. Circulation 2000;102:742-7. 